\title{
Aerosol delivery via invasive ventilation: a narrative review
}

\author{
Hui-Ling Lin ${ }^{1,2,3}$, James B. Fink ${ }^{4,5}$, Huiqing $\mathrm{Ge}^{6}$ \\ ${ }^{1}$ Department of Respiratory Therapy, Chang Gung University, Taoyuan; ${ }^{2}$ Department of Respiratory Care, Chang Gung University of Science and \\ Technology, Chiayi; ${ }^{3}$ Department of Respiratory Therapy, Chiayi Chang Gung Memorial Hospital, Chiayi; ${ }^{4}$ Division of Respiratory Care, Rush \\ University Medical Center, Chicago, IL, USA; ${ }^{5}$ Aerogen Pharma Corp., San Mateo, California, USA; ${ }^{6}$ Department of Respiratory Care, Sir Run Run \\ Shaw Hospital, School of Medicine, Zhejiang University, Hangzhou, China \\ Contributions: (I) Conception and design: HL Lin; (II) Administrative support: HL Lin, JB Fink; (III) Provision of study materials or patients: HL \\ Lin, H Ge; (IV) Collection and assembly of data: HL Lin; (V) Data analysis and interpretation: HL Lin, JB Fink; (VI) Manuscript writing: All \\ authors; (VII) Final approval of manuscript: All authors. \\ Correspondence to: Hui-Ling Lin, MSc, RRT, FAARC. 259 Wen-Haw 1st Rd, Guishan 33302, Taoyuan. Email: huilingrrt@gmail.com.
}

\begin{abstract}
In comparison with spontaneously breathing non-intubated subjects, intubated, mechanically ventilated patients encounter various challenges, barriers, and opportunities in receiving medical aerosols. Since the introduction of mechanical ventilation as a part of modern critical care medicine during the middle of the last century, aerosolized drug delivery by jet nebulizers has become a common practice. However, early evidence suggested that aerosol generators differed in their efficacies, and the introduction of newer aerosol technology (metered dose inhalers, ultrasonic nebulizer, vibrating mesh nebulizers, and soft moist inhaler) into the ventilator circuit opened up the possibility of optimizing inhaled aerosol delivery during mechanical ventilation that could meet or exceed the delivery of the same aerosols in spontaneously breathing patients. This narrative review will catalogue the primary variables associated with this process and provide evidence to guide optimal aerosol delivery and dosing during mechanical ventilation. While gaps exist in relation to the appropriate aerosol drug dose, discrepancies in practice, and cost-effectiveness of the administered aerosol drugs, we also present areas for future research and practice. Clinical practice should expand to incorporate these techniques to improve the consistency of drug delivery and provide safer and more effective care for patients.
\end{abstract}

Keywords: Invasive mechanical ventilation; aerosol therapy; inhaled drugs; lung deposition

Submitted Aug 04, 2020. Accepted for publication Nov 20, 2020.

doi: $10.21037 /$ atm-20-5665

View this article at: http://dx.doi.org/10.21037/atm-20-5665

\section{Introduction}

In comparison with aerosol administration for spontaneously breathing non-intubated subjects, administration of aerosols during mechanical ventilation is complicated by the presence of artificial airways, heated humidification, varying levels of positive pressure, flow patterns, and dynamics of controlled and spontaneous breathing, all of which affect aerosol delivery. Positive-pressure mechanical ventilators and shortacting bronchodilators were introduced with nebulizers for aerosolized drugs in 1950s (1). MacIntyre and colleagues quantified and compared the delivery of radiolabeled aerosol to intubated patients during invasive mechanical ventilation and spontaneously breathing subjects, reporting lung deposition rates of $3 \%$ and $12 \%$ of the total dose, respectively (2). This landmark study was the first to identify reduced aerosol deposition in intubated patients receiving jet nebulization during mechanical ventilation and speculated that higher doses might be required for effective aerosol administration to intubated patients.

Five years later, Fuller et al. confirmed similar low

^ ORCID: 0000-0002-8268-8907. 
deposition rates with a jet nebulizer synchronized with inspiration, while reporting that a pressured metered-dose inhaler (pMDI) and spacer yielded 4-fold greater lung deposition than that achieved with a jet nebulizer (3). Dhand and colleagues demonstrated a sustained bronchodilator response in intubated mechanically ventilated patients with chronic obstructive pulmonary disease (COPD) after administration of 4 puffs of inhaled bronchodilator by a pMDI with a spacer chamber, and reported no further increase in bronchodilator response with increased doses up to 28 puffs in a similar patient population (4).

With advances in aerosol devices as well as the technology underlying mechanical ventilators, the tremendous interest and research on aerosol delivery to mechanically ventilated patients as well as the use of simulated models has broadened our understanding of aerosol behavior to facilitate optimal practice. Therefore, this narrative review aimed to review current evidence to guide optimal aerosol delivery and dosing during mechanical ventilation as well as areas recommended for future research.

We present the following article in accordance with the Narrative Review reporting checklist (available at http:// dx.doi.org/10.21037/atm-20-5665).

\section{Selection of articles for review}

A literature search was conducted in PubMed/Medline, and Google Scholar (prior to March 31, 2020) to retrieve relevant articles. The search was conducted with following terms: "aerosol therapy AND mechanical ventilator" "nebulizers" "metered dose inhalers" "dry powder inhaler" "inhaled drug dose" "aerosol therapy AND ventilation mode" "aerosol particle size distributions". The search was limited to English Language articles.

\section{Factors differentiating aerosol delivery during invasive mechanical ventilation}

Aerosols behave differently in spontaneous breathing and invasive ventilation since the artificial airway and ventilator circuit also act as buffers to alter aerosol deposition. The characteristics of aerosol delivery to spontaneously breathing and invasively ventilated patients are summarized in Table 1.

\section{Artificial airways}

Invasive ventilation refers to the delivery of ventilation through an artificial airway. Endotracheal tubes (ETTs) passing through the mouth and vocal cords into the trachea are the most common mode of invasive ventilation, while a tracheostomy tube (TT) inserted through an incision into the trachea is commonly used when ventilation is required for an extended period of time. ETTs are produced in various lengths with internal diameters ranging from $2-12 \mathrm{~mm}$, in $0.5 \mathrm{~mm}$ increments, and lengths ranging from 12-28 cm (5). In contrast, TTs are considerably shorter $(10-12 \mathrm{~cm})$, and are available in a similar range of internal diameters. The outer diameter of these artificial airways is less than half of the internal diameter of the trachea.

After insertion, mucus and biofilms can accumulate on the tube surface, creating irregular surfaces and narrowing the diameter of the artificial airways. Pinciroli et al. assessed the diameter changes in an endotracheal tube after an average placement period of 7 days (6). The extubated ETTs had accumulated $0.71 \mathrm{~mL}$ of mucus, reducing the internal diameter by $0.4-1.0 \mathrm{~mm}$. The narrow diameter of the ETT and TT in comparison with the normal airway, in combination with the high inspiratory flows employed during mechanical ventilation alter aerosol delivery. Ari et al. quantified aerosol delivery through ETTs and TTs with a simulated ventilated adult model, and the results demonstrated a $3.9 \%$ lung dose through a TT and 3.2\% through an ETT with a jet nebulizer and a 14.7\% lung dose through a TT and $11.6 \%$ through an ETT with a pMDI (7). The size and length of the artificial airway should account for the reduced delivered drug dose; therefore appropriate dosing should be considered for optimal clinical response of the drug.

\section{Aerosol particle size characteristics and deposition}

The efficacy of the aerosolized drug depends on the dose deposited at the target site of action as well as its distribution in the lungs. Medical aerosols contain particles of many different sizes (heterodispersion), and their average particle size is expressed as a measure of a central tendency, such as mass median aerodynamic diameter (MMAD) or volume median diameter (VMD) (8). The deposition of aerosol depends on three key mechanisms: inertial impaction, gravimetric sedimentation, and Brownian diffusion. Inertial impaction occurs when suspended particles in motion collide and are then deposited on a surface; this is the primary mechanism for particles larger than $5 \mu \mathrm{m}$ during spontaneous breathing. Sedimentation occurs when aerosol particles are deposited due to gravity, and primarily occurs 
Table 1 Characteristics of aerosol delivery to spontaneously breathing and invasively ventilated patients

\begin{tabular}{lll}
\hline Characteristics & Spontaneously breathing & Invasive ventilation \\
\hline Airway & Oro-nasal upper airway & Artificial airway \\
Inspiration flow waveform & Sinusoidal & Descending, ascending or square \\
Inspiratory flow rate & $15-40 \mathrm{~L} / \mathrm{min}$ & Up to $100 \mathrm{~L} / \mathrm{min}$ \\
Interface of delivery & Mouthpiece/mask/nasal prongs & An adapter at airway or vent circuit \\
Inhaled Aerosol Temperature & Ambient & Heated to $\sim 37^{\circ} \mathrm{C}$ \\
Surrounding Humidity & Ambient & Humidified to $95-99 \%$ relative humidity \\
Aerosol particle size to reach lower airways & $2-5 \mu \mathrm{m}$ & $\sim 2 \mu \mathrm{m}$ \\
Aerosol reservoir & Naso pharynx & Circuit \\
Aerosol loss & Upper airways, exhalation to ambient & Artificial airway, ventilator circuit impaction/ \\
& & sedimentation
\end{tabular}

for deposition of particles sized 1-5 $\mu \mathrm{m}$. Brownian diffusion is the primary mechanism for deposition of small particles $(<3 \mu \mathrm{m})$, mainly in the respiratory region.

During invasive ventilation, aerosol behavior and deposition differ from those in spontaneous breathing due to the heat and moisture in the circuit, the contours of the ventilator circuit, narrower artificial airways, and inspiratory flow patterns. The circuit and artificial airway act as a baffle filtering out particles greater than $2 \mu \mathrm{m}$ as aerosols travel from the aerosol generator through the ventilator circuit and artificial airway, with larger particles deposited in the ventilator circuit and ETT (9-11). An ETT with the tip located approximately $2 \mathrm{~cm}$ above the carina can preferentially direct the aerosol flow to the right lung and increase particle deposition at the right main bronchus (12). Alzahrany et al. utilized a computer fluid dynamics model of flow structure under invasive ventilation with an ETT to simulate aerosol drug deposition. Figure 1 represents aerosol deposition during invasive mechanical ventilation, which showed that, with different flow waveforms, large particles are filtered out in the artificial airway. Therefore, with various drugs administered during ventilation, the drug action on the target site might be especially important.

\section{Aerosol generators used during mechanical ventilation}

The three existing classes of medical aerosol devices are nebulizers, pressurized metered dose inhaler, and dry powdered inhalers, with nebulizers further divided by design into pneumatic jet nebulizers, ultrasonic nebulizers, and vibrating mesh nebulizers. Additionally, soft mist inhalers have gained popularity since they are manufactured with a greater range of medications for the management of COPD patients, with clinicians also using them for mechanical ventilation of critically ill patients.

\section{Pneumatic jet nebulizer ( $\mathcal{F}$ )}

JNs are most commonly employed for aerosol delivery during mechanical ventilation because they are easy to use and relatively inexpensive. While most nebulizers require a driving gas flow $5-10 \mathrm{~L} / \mathrm{min}$, some nebulizers require flow as $2 \mathrm{~L} / \mathrm{min}$, such as MiniHeart Lo-Flo nebulizer (13). These low flow nebulizers require higher operating pressures to operate and may not work well with some compressors integral to mechanical ventilators. Using an external gas flow to operate a JN adds gas volumes that influences the operation of ventilator system by increasing tidal volumes and pressures delivered to the patient, increasing the work of breathing, and reducing the sensitivity of the patient interface $(14,15)$.

Advanced ventilators can perform nebulization synchronization, which diverts a fraction of the inspiratory flow to power the $\mathrm{JN}$ during inspiration. This method is preferred to deliver aerosols without interrupting ventilator performance during nebulization and is preferred over the use of an external gas source to continuously operate the $\mathrm{JN}$, which adds gas to the ventilator circuit independent of ventilator operation. Although a synchronized aerosol 

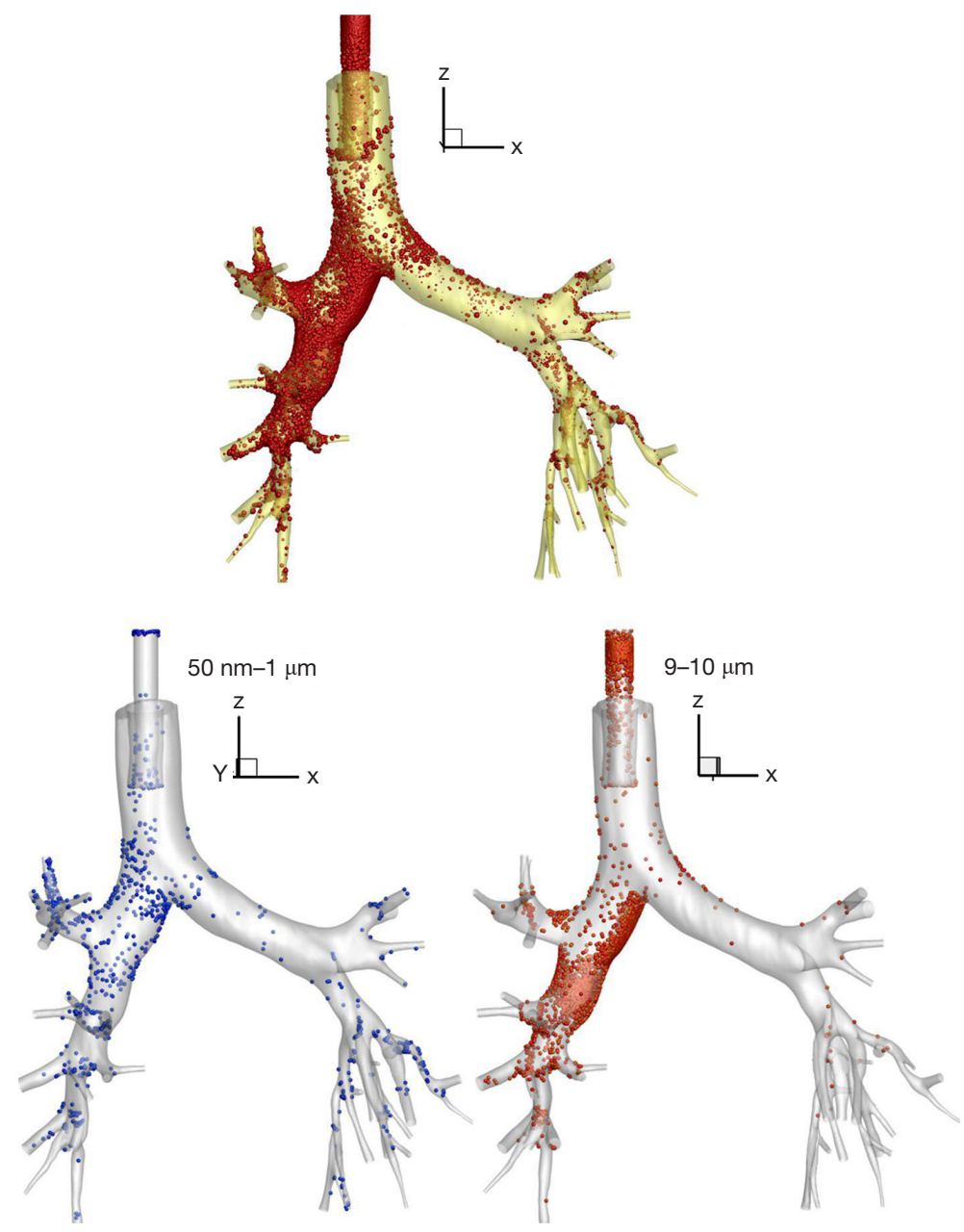

Figure 1 Particle deposition pattern during invasive ventilation. From Ref. (12) with permission.

may be less disruptive to mechanical ventilation, it is not clear whether it improves aerosol delivery. A study reported similar aerosol drug doses delivered with pneumatic nebulization generating aerosol continuously or in the inspiratory or expiratory phases (16), but the nebulization time of inspiratory intermittent synchronization was threefold greater than those in the other two modes.

\section{Ultrasonic nebulizers (USN)}

USNs use a piezoelectric crystal to generate an aerosol. The crystal transducer converts an electrical signal into highfrequency (1.2- to 2.4-MHz) acoustic vibrations. These vibrations are focused on the liquid above the transducer, where they disrupt the surface and create oscillation waves. The oscillation waves form a standing wave that generates a geyser of droplets that break free as fine aerosol particles, ranging from 5.5 to $7 \mu \mathrm{m}(8,17)$. Small-volume USNs are available, but are not commonly employed during mechanical ventilation because they are bulky, and costly (1). USNs are relatively inefficient for aerosolizing suspensions because suspensions that are larger than the aerosol particles remain in the medication cup.

The energy used to generate aerosols raises the solution temperature by $10-15{ }^{\circ} \mathrm{C}$ after 5 minutes of nebulization (18), and could degrade heat-sensitive medications (19). In a pilot, crossover design study, Harvey et al. compared pulmonary deposition by JNs and USNs to intubated patients under mechanical ventilation by using radiolabeled aerosol inhalation followed by gamma camera imaging (20). Their results showed that total lung aerosol deposition as a percentage of initial nebulizer activity 
was significantly greater with the USN $(5.3 \% \pm 1.4 \%$ vs. $2.3 \% \pm 0.9 \%)$.

\section{Vibrating mesh nebulizer (VMN)}

VMNs are described as active and passive, but only active VMNs are currently available for use with invasive ventilation. Active VMNs use a dome-shaped aperture plate containing more than 1,000 funnel-shaped apertures with a surrounding washer attached to a piezoceramic element. Electrical energy applied to the piezoceramic element vibrates the attached aperture plate at a frequency of approximately $130 \mathrm{kHz}$, vibrating the aperture plate up and down by approximately $1 \mu \mathrm{m}$. The plate actively pumps liquid through the apertures, where it is broken into fine droplets between 3 and $5 \mu \mathrm{m}$ in size (8). The VMN is associated with a higher efficiency than a JN and USN partly due to the lower residual volume of drug in the reservoir $(0.1-0.5 \mathrm{~mL})$. Due to the lower frequency and power requirement than USNs, the VMN does not add much heat to the medication, thereby reducing the risk of denaturing proteins (21).

The possibility of electronic operation without an external gas source to the closed ventilator circuit while maintaining delivery parameters such as volumes and pressures has been a major attraction for clinicians converting from JN to VMN use (14). Radiolabeled studies of VMNs during IMV showed $12 \%$ to $15 \%$ lung deposition with volume- and pressure-control ventilation, respectively (22).

\section{Pressurized metered-dose inhaler (pMDI)}

pMDIs are small, portable, convenient, multi-dose devices that use a propellant under pressure to deliver a metered dose of aerosol through an atomization nozzle. pMDIs contain several components, including a canister, propellant, drug formulation, metering valve, and actuator. Since the liquid suspension is forced out of the pMDI, it forms a plume, which the propellants vaporize within $20 \mathrm{~ms}$.

For pMDI use during mechanical ventilation, synchronization with inspiration is essential to ensure greater and more consistent delivered doses. Additionally, pMDIs are not designed for use in closed pressurized ventilator circuits, necessitating third-party actuator devices ranging from simple adapters with a port and single nozzle to more complex spacer chambers showing performance variations between adapter designs. Rau et al. first illustrated increased drug delivery with a reservoir chamber for pMDI placement in the inspiratory limb (23). Although manufacturers typically use a pMDI inline adaptor and reservoir to improve aerosol delivery, Rau et al. further evaluated the differences between commercially available adaptors/reservoirs and demonstrated that a bidirectional adaptor was equally efficient as a reservoir for albuterol pMDI delivery during invasive ventilation (24). Waugh et al. evaluated changes in respiratory airway resistance, peak expiratory flow rate, and work of breathing in patients under invasive ventilation after receiving a pMDI bronchodilator delivered through different types of spacers (25), and their results demonstrated that different pMDI spacers affected drug delivery and the subsequent clinical responses. The influence of inline spacers was explained by Smyth et al., who illustrated the influences of drug delivery due to changes in fluid particle dynamics from the shape, internal volume, and the spray direction toward the ventilator (26).

The pMDI propellant and drug formulation change aerosol behavior and further influence drug deposition. Fink and colleagues evaluated chlorofluorocarbon (CFC)propelled MDI and hydrofluoroalkane (HFA)-propelled MDI during mechanical ventilation (27). The plume velocities and valve stem diameters of CFC- and HFApropelled MDIs were different; therefore, the use of an MDI canister placed in the actuator designed for the other formulation altered the particle size. Radiolabeling studies with a pMDI and the spacer chamber during IMV in COPD patients reported a lung deposition rate of $11 \%$ (3).

\section{Dry powder inbaler (DPI)}

Commercially available passive DPIs require a relatively high sustained inspiratory flow $>30 \mathrm{~L} / \mathrm{min}$ to release and deaggregate powders from a capsule or packet and have not been widely used for ventilated or intubated patients (28). A manual resuscitator bag was used in two studies to generate sufficient flow to deliver a powder formulation through the ETT or TT, and through a mechanical ventilator $(29,30)$. In both studies, a relatively high drug dose with fine particles could be delivered in vitro through the artificial airway, but neither study simulated exhaled humidity; therefore, drug delivery may be lower in the humidified circuits employed in vivo.

\section{Soft mist inbaler (SMI)}

The soft mist inhaler is a propellant-free, mechanically 


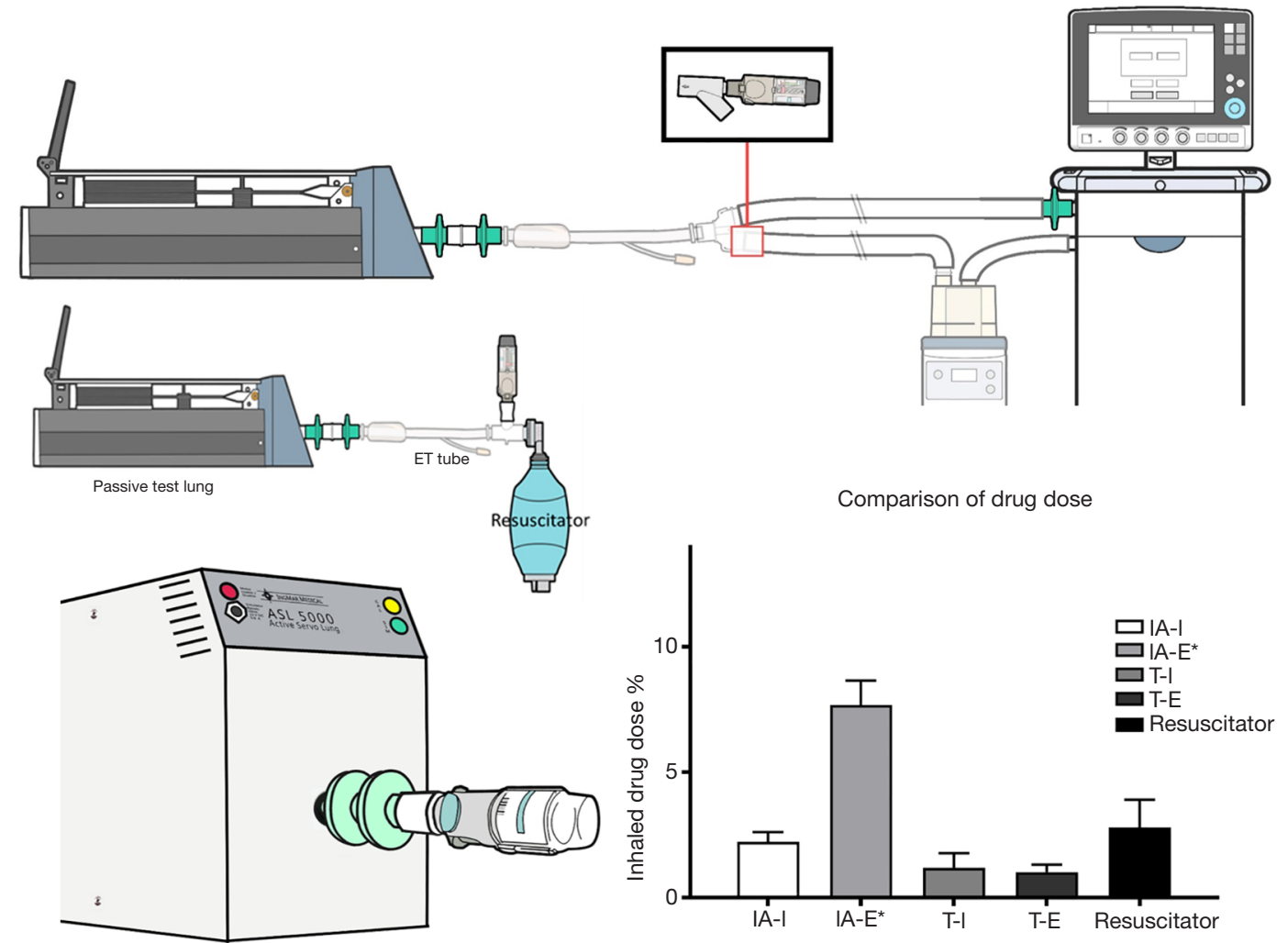

Figure 2 Comparisons of soft moist inhaler with a commercial adaptor actuated at expiratory phase generated the highest delivered dose with a commercial adaptor. From Ref. (35) with permission.

operated multiple-dose device that nebulizes a liquid drug solution through an uniblock, allowing the drug solution to produce aerosol in a slow-moving cloud with a spray time of $1.0-1.5 \mathrm{~s}$ (31). The low aerosol velocity reduces oropharyngeal deposition and can generate more than $60 \%$ of the fine-particle fraction $(\leq 5.0 \mu \mathrm{m})$ for the delivered bronchodilator independent of inspiratory effort $(31,32)$.

The first study performed using flow profiles of mechanically ventilated COPD patients in vitro evaluated SMI delivery with a prototype design of a valvefree inline SMI adapter, modified connectors, and the holding chamber for a pMDI metered-dose inhaler and reported that the prototype inline adaptor delivered greater fine particle doses than other accessory device combinations (33). Suggett used a ventilator circuit with a prototype SMI adaptor for an SMI delivering a combination of salbutamol and ipratropium, but this adaptor is not commercially available at the time of publication (34). Fang and colleagues used a commercial adaptor, shown in Figure 2, for SMI and reported $7.68 \% \pm 0.98 \%$ total delivered dose with actuation during expiration, which was still 3 -fold lower than that with the spontaneous model $(22.2 \% \pm 0.4 \%)$; however, the relatively low inhaled dose of aerosol from the SMI in the study and the volume loss from the circuit raised concerns whether sufficient drug delivery can be achieved to justify its use during mechanical ventilation (35).

The JN, VMN, and pMDI are the most commonly used aerosol devices during invasive ventilation. Studies have reported delivered drug doses of approximately $3-5 \%$ of the total administered dose for JNs, $17-35 \%$ for VMNs, and $10-20 \%$ for pMDIs with inline spacer $(2,21,36-39)$ distal to an ETT. In addition to the higher delivered dose, the VMN has attracted interest for delivering aerosol during invasive ventilation because it can stay in line for up to 28 days without needing to "break" the circuit to add medication or clean the nebulizer; it has a sealed reservoir resistant to contamination from condensate and secretions in the ventilator circuit; and it does not add external flow.

Many studies have compared the delivery efficiencies 
of those 3 aerosol generators both in vitro and with urine assays. ElHansy and colleagues compared aerosol delivery with five different types of aerosol generators during invasive ventilation, analyzing drugs in patient urine samples $30 \mathrm{~min}$ and $24 \mathrm{~h}$ after administering the treatment and by collecting drug-deposited doses on a filter in an ex vivo model (21). Their results showed that the pMDI yielded significantly greater proportional urine doses and in the ex vivo model, while the JN delivered the lowest drug doses in both models. Moustafa and colleagues determined the effects of three types of aerosol generators and humidity changes during aerosol delivery on clinical outcomes and the status of mechanically ventilated patients, and their results showed no significant difference among generators and humidity conditions in relation to the duration of ICU stay and mechanical ventilation (40). Table 2 lists the comparisons of aerosol generators during invasive ventilation.

\section{Factors affecting aerosol delivery during invasive ventilation}

Numerous factors influence aerosol delivery efficiency during invasive ventilation, including heat and humidity, mode of nebulization, position of nebulizer in the ventilator circuit, gas flow, and bias flow.

\section{Heat and humidification}

Ventilators commonly deliver dry and anhydrous gases such as compressed oxygen provided by high-pressure oxygen cylinders or liquid oxygen available through hospital piping systems, which also has a very low absolute humidity. To prevent mucosal damage to the airways, two strategies are used to heat and humidify this largely anhydrous incoming gas: (I) active heated humidification, and (II) passive heat moisture exchange (HME). Active heated humidifiers heat a mass of water that is then placed in contact with the dry cold gas as it moves into the ventilator circuit toward the patient, with a goal of delivering $>90 \%$ relative humidity at $35-40{ }^{\circ} \mathrm{C}$.

In contrast, HME captures heat and moisture from the patient's expired gas and returns up to $70 \%$ of both to the gas delivered to the patient during the next inspiration (6). The level of heat and relative and absolute humidity in the inhaled gas is associated with changes in the mucosa of the airway, particle size characteristics, and reduced aerosol deposition (41).
The presence of heat and humidity associated with water molecular pressure in a ventilator circuit has been demonstrated to reduce as much as $50 \%$ of the aerosol drug dose $(8,10,39,42)$. To overcome the effect of humidification, clinicians may turn off the heater during aerosol delivery. However, Lin and colleagues demonstrated that turning off the humidifier for up to $40 \mathrm{~min}$ prior to pMDI administration did not increase aerosol delivery (39). Recently, Moustafa and colleagues illustrated the effect of humidity on aerosol delivery by measuring secreted urinary salbutamol pharmacodynamics (43). Thirty-six mechanically ventilated patients received bronchodilator delivered by 3 aerosol generators with or without humidification. Drug levels of urinary salbutamol were compared and revealed that humidity does not influence bioavailability with any of the devices tested. They further determined the influence of humidity on clinical response and the durations of hospitalization and mechanical ventilation and reported that aerosol delivery with and without humidification had no significant effect on those clinical outcomes (40). Thus, we recommend against interruption of the heated humidifier during aerosol administration.

The hydroscopic/hydrophobic material in an HME captures exhaled heat and humidity, which are recycled to the inhaled gas. Some HMEs incorporate additional filters (HME-F). HME-Fs should be removed from the patient airway during aerosol administration. To minimize the removal of HME and open the ventilator circuit, some HMEs have been redesigned to reroute aerosols from the ventilator circuit to the distal part of an ETT during aerosol administration. Ari and colleagues evaluated 3 HMEs, 1 nonfilter HME and 2 filter HMEs (44). They found that the delivered dose with the nonfilter HME was approximately $35 \%$ of that with no HME (3.5\% vs. $5.5 \%$ for JNs, and $6.6 \%$ vs. $10.6 \%$ for $\mathrm{VMNs}$ ), In contrast filter HMEs reduced delivery by $>90 \%$, allowing $<0.5 \%$ of the total dose to be delivered distal to the artificial airway. The most efficient use of an HME is to place the aerosol device between the HME and patient airway.

\section{Aerosol device placement}

Aerosol generator placement influences the efficiency of aerosol drug dose delivery through the artificial airway into the lungs. While greater dose delivery with a pMDI and USN were achieved with placement in the inspiratory limb closest to the ETT, a greater drug dose was reported with a $\mathrm{JN}$ placed at the inlet of the heated humidifier (38). 


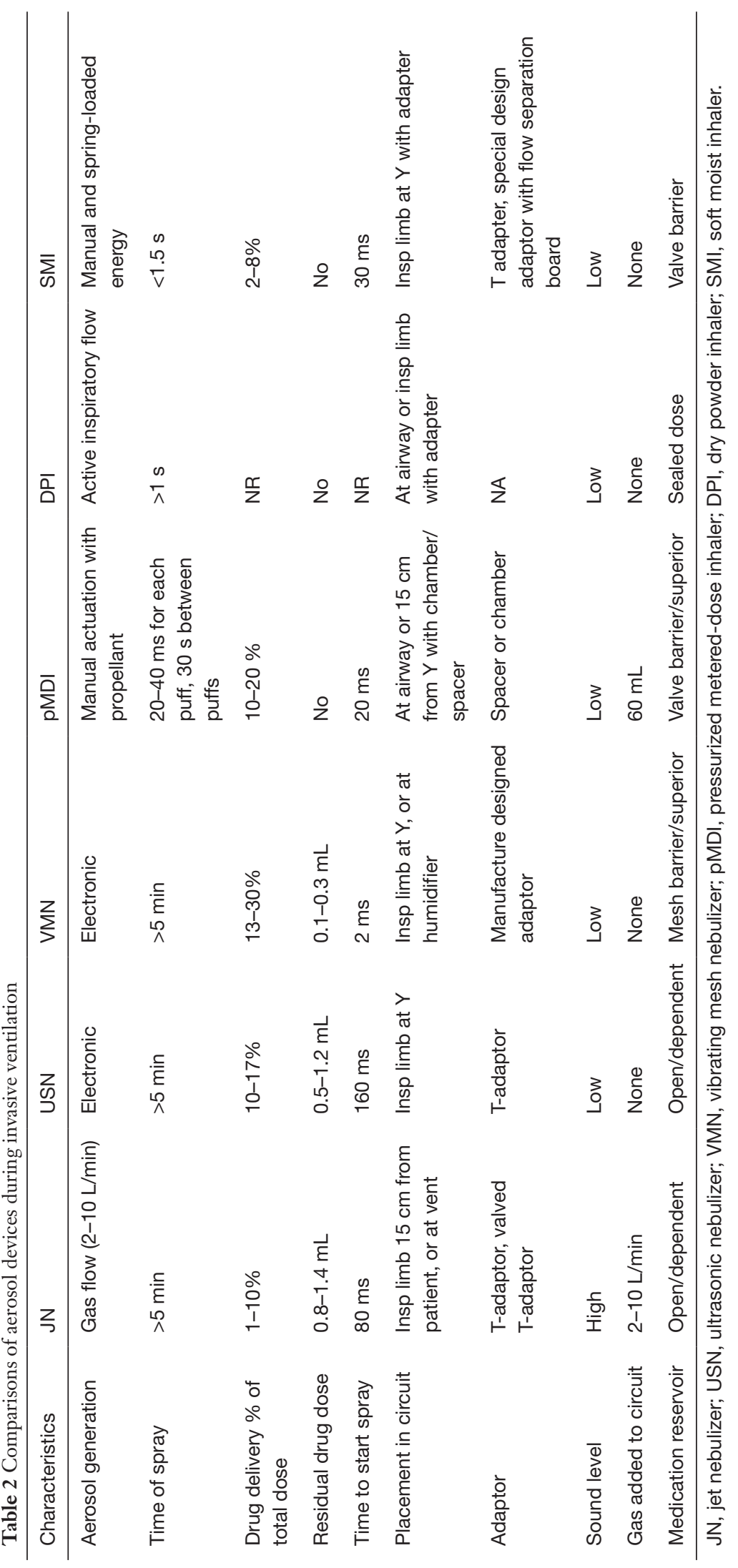


O'Doherty first illustrated that the addition of an aerosol storage chamber (reservoir) to a JN increased the delivered drug dose (45). In 2000, Fink et al. reported higher drug delivery with a JN placed before a humidifier compared to standard placement proximal to the patient airway; however, this was not the case with USN (46). Moraine, who compared urinary ipratropium levels in mechanically ventilated adults, reported that the position of a USN in the ventilatory circuit had no effect on the pulmonary bioavailability of ipratropium to patients without known preexisting respiratory disease (47). In 2010, Ari and colleagues evaluated aerosol delivery generated by a JN, $\mathrm{VMN}$, and $\mathrm{pMDI}$ in an in vitro model of adult mechanical ventilation, with and without heated humidity $(38,48)$. Their results showed greater delivered doses of $17 \%$ with a pMDI, USN, and VMN placed $15 \mathrm{~cm}$ from the Y-piece in the inspiratory limb of the ventilator circuit while JN efficiency (5\%) was the greatest when placed $15 \mathrm{~cm}$ from the ventilator. The authors speculated that the continuous gas from the jet nebulizer pushes aerosol into the inspiratory limb between inspirations, acting as a reservoir retaining aerosols during the expiratory phase.

With advances in ventilator design, the introduction of bias or base flow constantly circulating through the ventilator circuit has complicated fluid dynamics and further influenced aerosol drug delivery. Ari hypothesized that bias flow could change the delivery efficiency of a JN and VMN placed in the inspiratory limb either close to the patient, or back before the heated humidifier (48). Comparing 2 and $5 \mathrm{~L} / \mathrm{min}$ bias flows, they reported that both VMN and JN were more efficient when placed at the vent, while efficiency decreased with bias flow when they were placed proximal to the patient. These findings were confirmed in pediatric ventilators by Berlinski et al., who compared $2 \mathrm{JNs}$, a USN, and a VMN placed at 4 different positions of the ventilator circuit at $2 \mathrm{~L} / \mathrm{min}$ bias flow, and reported a trend for large deposition with VMN placement on the outlet $v$ s. inlet side of the humidifier (49).

In contrast, Anderoson and colleagues noted no differences in drug deposition when placing a JN between the humidifier inlet and outlet, but these positions resulted in greater deposition compared with those obtained with placement in the inspiratory limb and between the ETT and Y-piece (50). DiBlasi et al. compared nebulizer position with respect to the infant ventilator circuit and parameters and reported high deposition with a VMN placed at the airway $(10.8 \%)$ than at the humidifier (3\%). The authors speculated that the smaller tidal volumes $(20 \mathrm{~mL})$ required
$>5$ respiratory cycles for aerosol advancement from the humidifier to the patient airway, during which the majority of aerosol was lost in the circuit (51).

\section{Ventilator mode and settings}

A ventilator generates distinct flow patterns and velocities with different parameter settings, and the flow changes aerodynamics during aerosol delivery, resulting in altered delivered drug dose. Dugernier and colleagues compared lung deposition of radiolabeled aerosol during invasive mechanical ventilation, and randomly allocated 17 postoperative patients without pulmonary disease to two ventilation modes (22). Lung deposition $5 \%$ greater than the nominal dose toward the right lung was achieved with volume-controlled ventilation than with pressure-support ventilation; however, a significantly greater drug dose was deposited on the ETT and tracheal area with pressuresupport ventilation, which may be attributed to the higher inspiratory flow rate. Studies have demonstrated that a slower inspiratory flow increases aerosol drug dose with a pMDI, JN, or $\mathrm{VMN}$; in general, the delivered drug is affected by the inspiratory flow pattern $(27,52,53)$.

Airway pressure release ventilation (APRV) has been used to maintain a higher level of airway pressure to treat patients with refractory hypoxemia. With the APRV mode, a fast inspiratory flow generates a set high pressure, after which a constant flow is maintained for 4-5 s. Ge and colleagues compared aerosol delivery by a VMN during pressurecontrolled and APRV modes with and without spontaneous breathing (54). The results showed that the APRV mode with spontaneous effort placing the VMN at the humidifier inlet yielded a higher delivered drug dose $(34.1 \%)$ than the PCV mode (29.8\%), PCV with bias flow (23.6\%), and APRV mode (23.1\%). They also noted correlations between the delivered dose and minute ventilation.

Mouloudi and colleague evaluated the influence of ventilator settings for inspiratory flow rate, tidal volume, and end-inspiratory pause to mechanically ventilated COPD patients; their results showed that manipulation of ventilator settings did not alter the physiological responses to the bronchodilators (55-57). This may be secondary to the drug used, and the plateau response to bronchodilators did not change with increased doses or efficiency of deposition. The discrepancies and correlation between in vitro and in vivo studies with a wide range of ventilation modes and aerosol devices warrant further investigation.

Ventilators generate flow differently, which can influence 


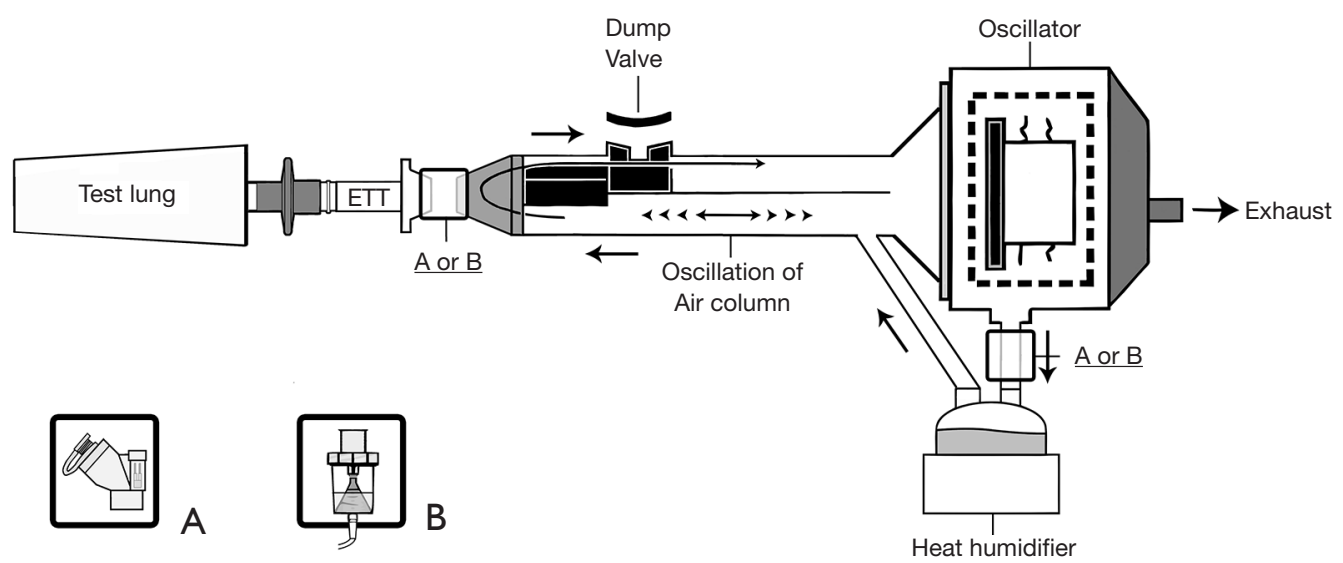

Figure 3 Study experimental scheme of the study on HFVO. Both nebulizers delivery greater drug dose placing at proximal to the endotracheal tube, and a VMN delivers greater drug dose then a JN. From Ref. (58) with permission.
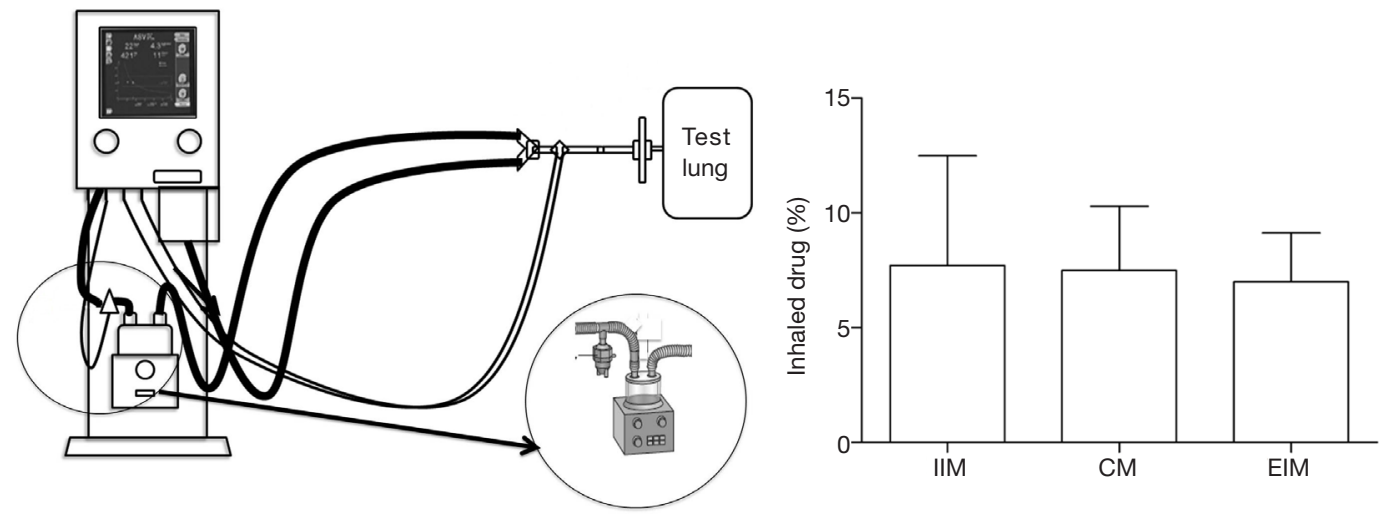

Figure 4 Comparison of inhaled drug mass among 3 modes of nebulization and the experimental set up. Inhaled drug dose was similar across three nebulization modes. From Ref. (16) with permission.

aerosol delivery. Fang and colleagues determined the efficiency of aerosol delivery with different lung parameters during simulated neonatal, pediatric, and adult highfrequency oscillatory ventilation (HFOV) (58) (Figure 3). A JN and a VMN were placed either between the ETT and the Y-piece of the inspector limb or at the inlet of a humidifier chamber. Delivered doses were 3\% and 22.7\% of the nominal dose by a JN and a VMN retrospectively placed at the proximal position, and $0-0.6 \%$ of the total dose when the devices were placed at the distal end. With a greater base flow circulating in the ventilator system and the turbulence generated with HFOV, the aerosol generator should be placed at the ETT for greater aerosol delivery. These findings were consistent with a model of neonatal HFOV, where placement of a VMN at the humidifier delivered $<1 \%$, while placement between the oscillator circuit and airway delivered 30\% (51).

\section{Synchronizing aerosol generation with the breathing cycle}

Aerosol devices generate aerosols with different characteristics and lengths of time for administration. Synchronization of aerosol generation with inspiration through the ventilator system has been assumed to facilitate greater drug delivery. Many models of ventilators provide options for synchronization of aerosol delivery with a JN. Wan and colleagues, using a Hamilton Galileo ventilator, compared drug delivery by a JN synchronized with the following three modes: inspiratory intermittent nebulization mode synchronized with inspiration phase, continuous 
nebulization mode, and expiratory intermittent nebulization mode (16) (Figure 4). While the delivered drug doses among these three modes were similar, the nebulization time with intermittent nebulization during inspiration was 2-fold longer than that during continuous nebulization. Thus, expiratory intermittent synchronization and continuous nebulization should be considered to reduce treatment time.

\section{Density of the inbaled gas}

Helium-oxygen (Heliox) gas is a low-density gas mixture and is used to carry oxygen through severely obstructed airways caused by post-extubation stridor, status asthmatics, and respiratory syncytial virus bronchiolitis (59). Heliox inhalation improves ventilation and oxygenation, reduces airway resistance and work of breathing, and decreases $\mathrm{CO}_{2}$. When Heliox is used as the driving gas for the JN, aerosol output changes, but at sufficient gas flow, the generation of aerosol increases, and deposition of aerosol to the lung is increased due to decreased deposition within the delivery equipment, mouth, and throat (60). Although the VMN does not require gas power, O'Callaghan and colleagues reported that the output of a VMN and aerosols with particle size $<5 \mu \mathrm{m}$ were increased by entraining Heliox filled in a reservoir bag (61). Additionally, a higher minute volume was achieved, which might increase aerosol delivery to the lung periphery. Nevertheless, controversies exist regarding the benefit of Heliox-driven nebulization to asthma exacerbation patients with spontaneous breathing patterns (62).

The use of Heliox to deliver aerosols during mechanical ventilation has been studied in pediatric and adult models (63-65). Goode et al. found that Heliox in the ventilator circuit increased aerosol delivery for both pMDIs and nebulizer by up to $50 \%$ over oxygen/air alone in the mechanically ventilated model (65). Use of 80:20 helium:oxygen at the air inlet of a ventilator allowed adjustment of $\mathrm{FiO}_{2}$ to the patient; however, Heliox is not effective for aerosol administration below 50\% (62). Not all ventilators work well with Heliox, since their pressure and flow valves may be based on characteristics of air and oxygen. Introduction of Heliox into some mechanical ventilators alters tidal volume, minute volume, alarms, and other parameters (66). Aerosol therapy using the Heliox mixture during invasive ventilation requires further precautions based on benefit and cost. Helium is a rare and costly gas, and when Heliox is used to treat severe airway obstruction, aerosol administration may offer additional benefits. In general, the use of Heliox to only increase aerosol delivery efficiency may not be cost-effective.

\section{Impact of exhaled aerosols and fugitive emission during mechanical ventilation}

While as much as $30 \%$ of aerosols are typically inhaled, a greater proportion of administered aerosols will be exhausted, leading to concerns regarding secondhand exposure of healthcare providers and families to medical aerosols (67). However, surveys reported that the usage rate of protective filters on the expiratory limb of ventilator circuits was only $24-40 \%(68,69)$.

Ari and colleagues quantified the amount of aerosols collected at the exhaust outlet of mechanical ventilators operated with and without filters in the expiratory limb (70). The study demonstrated exhaust aerosol percentages as high as $45 \%$ of the administered dose without a filter and $4-6 \%$ with a filter, which had a filtration efficiency of $>99.99 \%$ to 2.0 microns. The exhaled drug dose was much lower at $0.25 \%$ with a proprietary highefficiency particle filter, which has a $99.97 \%$ filtration efficiency to 0.3 microns at $100 \mathrm{~L} / \mathrm{min}$ flow. Therefore, the use of a high-efficiency particulate air (HEPA) filter at the expiratory limb is encouraged. If the HEPA filter is not available, at least an electrostatic filter should be placed during aerosol therapy.

While a HEPA filter prevents aerosol exhaustion, it may also increase the resistance of the ventilator system after aerosol therapies. A previous in vitro study evaluated pressure changes after repeated administration of aerosolized $10 \%$ acetylecysteine or $2 \%$ saline (71). The study reported that airway pressure drastically increased to $40 \mathrm{cmH}_{2} \mathrm{O}$ after repeated aerosolized acetylecysteine for 45 doses. The ventilator parameters should be monitored closely when administering aerosolized viscus drugs which may form crystal on the filter.

\section{Areas for future research and practice}

\section{Dose-response/toxicity correlation}

Dose response evaluations of most approved aerosolized drugs were performed in patients with spontaneous breathing. However, an earlier study reported only $3 \%$ of the lung dose in mechanically ventilated patients vs. $12 \%$ in spontaneously breathing patients (2). The therapeutic and adverse effects of the inhaled bronchodilator have 
been evaluated. Marik et al. compared the pulmonary bioavailability of albuterol delivered by the nebulizer, the metered-dose inhaler (MDI) and spacer, and the right-angle MDI adaptor in ventilated patients by using urinary analysis of drug levels (72). The recovered albuterol doses in the urine were approximately $38 \%$ with MDI and spacer and $16 \%$ with the nebulizer, which was similar to the findings of previous bench studies. Another study compared the bronchodilator response of albuterol administered via a pMDI and spacer versus JN to mechanically ventilated patients with COPD (73), and reported improved airway resistance persisting for 90-120 minutes with both devices.

Aerosolized drug delivery during mechanical ventilation is considered an off-label use, and specific drug doses for these patients remain controversial. For example, albuterol was approved with 2-4 actuations via a pMDI for bronchodilation treatment. Dhand first determined the response dose of albuterol after administering 4 puffs to ventilated patients (4). Combinations of inhaled medications, such as long-acting beta agonists with corticosteroids, are standard regimens for COPD patients with severity greater than group C (74). However, no specific dose is recommended for these patients once they are intubated for acute exacerbation of COPD.

\section{Discrepancies in practice related to aerosol delivery through mechanical ventilation}

In a large survey on aerosol therapy in intensive care units (ICU) in Europe, approximately 30\% out of 2,808 patients received aerosol therapy, mostly in medical ICUs (68). Among these, 56\% reported using JNs, followed by pMDIs (23\%), USNs (10\%), and VMNs (10\%). Most patients $(82 \%)$ received bronchodilators, followed by corticosteroids (13\%), anti-infectious drugs (5\%, primarily colistin), and mucolytics (3\%, primarily acetylcysteine), and $38 \%$ of patients received $>2$ medications. Another recent survey conducted in China revealed bronchodilators $(64.8 \%)$ were the most administered drugs, followed by mucolytic agents (44.2\%), corticosteroids (43.4\%), and antibiotics (16.5\%), using USNs (48.3\%), JNs (39.2\%), VMNs (14.6\%), and pMDIs (15.4\%) (69). The discrepancies between these two studies could be attributed to physician training, drug/device availability, and insurance system coverage. Reimbursement for medical expenses by insurers in Europe and North America is based on packages according to disease categories versus payment for services in China.

A multi-center randomized trial compared on-demand $v s$. routine nebulization of acetylcysteine with salbutamol to patients receiving invasive ventilation (75) and showed no significant difference in ventilator-free days, length of stay or mortality, or the incidence of pulmonary complications. The authors concluded that on-demand nebulization may be a reasonable alternative to routine nebulization.

\section{Cost-effectiveness of the therapy}

Device selection should be based on multiple factors, including the amount of the dose delivered, cost of nebulizer, cost of drug, and time required to administer. Table 3 provides a guide on the costs of commonly used drugs and recommended devices. For example, Liu and colleagues reported one dose of colistin delivered by a $\mathrm{VMN}$ was superior to two doses of colistin delivered by a JN (12). They calculated the costs based on the results, and reported two to four additional vials $(\$ 50-\$ 100)$ required with a JN per day, increasing medication costs by $\$ 350-\$ 700$ for a 7-day course of colistin. Although a VMN is more expensive than a JN, the total cost for a week of treatment with a VMN would remain lower than that with a JN. Clinicians have to thus balance availability and costs to identify the most cost-effective aerosol therapy.

\section{Optimization of aerosol administration to invasively ventilated patients}

Although many factors need to be considered for optimization of aerosol administration to invasively ventilated patients, we provide a guide for choosing the optimal technique in Table 4.

\section{Conclusions}

Since the advent of modern mechanical ventilation, medical aerosol administration has been a part of patient care. With evaluations of both ventilator and aerosol device technology, researchers have explored the various factors affecting aerosol delivery and evolved strategies to optimize drug delivery to the lung of ventilated patients. Thus, delivery efficiencies have increased from $<1 \%$ to more than $30 \%$, and our abilities continue to expand. Clinical practice should expand to incorporate these techniques to improve the consistency of drug delivery and provide safer and more effective care for patients. 
Table 3 Costs of commonly used drugs and devices during mechanical ventilation

\begin{tabular}{|c|c|c|c|}
\hline Class of drug & Drug & Cost/dose & Device for administration \\
\hline \multirow[t]{4}{*}{ Short-acting Bronchodilator } & Albuterol solution & $\$ 2.01$ & $\mathrm{JN}, \mathrm{VMN}, \mathrm{MDI}+$ spacer \\
\hline & Albuterol MDI & $\$ 0.3$ & \\
\hline & Levalbuterol MDI & $\$ 0.31$ & \\
\hline & Combivent & $\$ 0.25-2.37$ & $\mathrm{JN}, \mathrm{SMI}+$ adaptor \\
\hline \multirow[t]{2}{*}{ Anticholinergic } & Ipratropium bromide & $\$ 0.18$ & JN, VMN \\
\hline & Tiotropium bromide & $\$ 11.98$ & SMI \\
\hline Corticosteroids & Budesonide & $\$ 9.25$ & $\mathrm{JN}$ \\
\hline \multirow[t]{2}{*}{ Combined drug } & Fluticasone/salmeterol & $\$ 2.34$ & MDI + spacer \\
\hline & Budesonide/formoterol & $\$ 2.25$ & MDI + spacer \\
\hline Antibiotics & Colistin (IV) & $\$ 24$ & JN, VMN \\
\hline \multirow[t]{3}{*}{ Pulmonary hypertension } & Epoprostenol (IV) & $\$ 23 / \mathrm{mL}$ & VMN \\
\hline & Treprostinil (IV) & $\$ 50.6 / \mathrm{mL}$ & \\
\hline & Iloprost inhalation solution & $\$ 140.94$ & VMN \\
\hline
\end{tabular}

Cost of delivery system: $\mathrm{JN}=\$ 1-2, \mathrm{USN}=\$ 200, \mathrm{VMN}=\$ 40, \mathrm{pMDI}$ spacer $=\$ 6-10 . \mathrm{JN}$, jet nebulizer; USN, ultrasonic nebulizer; VMN, vibrating mesh nebulizer; pMDI, pressurized metered-dose inhaler.

Table 4 Optimal technique for aerosol drug delivery to mechanically ventilated patients

- Select the appropriate drug for the patient.

- Select the aerosol device to be used, and determine where to position the device, based on patient size, ventilator type and mode, bias flow, and appropriate particle size for drug action target site etc.

- Based on the above, calculate the nominal dose required to achieve target lung dose.

- HME: For filter HME, remove HME from between the aerosol generator and the patient. If using an HME known to be aerosol permeable it may remain in the circuit, but will reduce inhaled dose by up to $40 \%$-adjust nominal dose accordingly.

- Active Heated Humidifier - if using heated humidifier, do not turn off or disconnect before or during treatment.

- Connect the nebulizer to a gas or power source, as appropriate.

- For jet nebulizer (including SVN): use gas source on ventilator to synchronize nebulization with inspiration, if available; otherwise, set gas flow 6 to $10 \mathrm{~L} / \mathrm{min}$ as recommended on nebulizer label for continuous nebulization, and adjust ventilator volume or pressure limits and alarms to compensate for flow and volume added to the circuit during aerosol administration. Use a valved T-adaptor to avoid break of the circuit closed system to add medication or clean nebulizer.

- For USN and VM nebulizer: Attach power source and cable from controller - no parameter or alarm adjustment required.

- For pMDI: Place adapter or spacer chamber in the inspiratory limb. Shake and prime pMDI prior to use, connect to spacer or adapter; actuate at beginning of inspiration. Wait 30-60 seconds between actuations. Remove canister and shake after 4 actuations.

- Observe aerosol cloud for adequate aerosol generation during nebulization.

- After dose is administered, remove open cup aerosol generator from the ventilator circuit. VMN may remain in circuit per manufacturer recommendations.

- Return ventilator settings and alarms to previous values.

- Ensure there is no leak in the ventilator circuit.

- Observe signs of increased airway resistance after aerosol therapy which may indicate a blockage of expiratory filter.

HME, heat and moisture exchanger; SVN, small volume nebulizer; USN, ultrasonic nebulizer; pMDI, pressurized metered-dose inhaler. 


\section{Acknowledgments}

Funding: None.

\section{Footnote}

Provenance and Peer Review: This article was commissioned by the editorial office, Annals of Translational Medicine for the series "Medical Aerosol in Acute and Critical Care". The article has undergone external peer review.

Reporting Checklist: The authors have completed the Narrative Review reporting checklist. Available at http:// dx.doi.org/10.21037/atm-20-5665

Conflicts of Interest: All authors have completed the ICMJE uniform disclosure form (available at http://dx.doi. org/10.21037/atm-20-5665). The series "Medical Aerosol in Acute and Critical Care" was commissioned by the editorial office without any funding or sponsorship. JBF served as the unpaid Guest Editor of the series and is Chief Science Officer for Aerogen Pharma Corp. The authors have no other conflicts of interest to declare.

Ethical Statement: The authors are accountable for all aspects of the work in ensuring that questions related to the accuracy or integrity of any part of the work are appropriately investigated and resolved.

Open Access Statement: This is an Open Access article distributed in accordance with the Creative Commons Attribution-NonCommercial-NoDerivs 4.0 International License (CC BY-NC-ND 4.0), which permits the noncommercial replication and distribution of the article with the strict proviso that no changes or edits are made and the original work is properly cited (including links to both the formal publication through the relevant DOI and the license). See: https://creativecommons.org/licenses/by-nc-nd/4.0/.

\section{References}

1. Fink JB, Ari A. Aerosol therapy in mechanically ventilated patients. ISAM Textbook of Aerosol Medicine. Rochelle, NY: International Society of Aerosols in Medicine (ISAM)/ Mary Ann Libert Publishing, Inc., 2015:947-86.

2. MacIntyre NR, Silver RM, Miller CW, et al. Aerosol delivery in intubated, mechanically ventilated patients. Crit Care Med 1985;13:81-4.
3. Fuller HD, Dolovich MB, Posmituck G, et al. Pressurized aerosol versus jet aerosol delivery to mechanically ventilated patients. Comparison of dose to the lungs. Am Rev Respir Dis 1990;141:440-4.

4. Dhand R, Duarte AG, Jubran A, et al. Dose-response to bronchodilator delivered by metered-dose inhaler in ventilator-supported patients. Am J Respir Crit Care Med 1996;154:388-93.

5. Altobelli N. Airway management. In: KacMarek RM, Stoller JK, Heuer AJ, editors. Egan's Fundamentals of Respiratory Care 11th ed. St. Louis, MO: Elsevier-Mosby 2017:749-52.

6. Pinciroli R, Mietto C, Piriyapatsom A, et al. Endotracheal tubes cleaned with a novel mechanism for secretion removal: a randomized controlled clinical study. Respir Care 2016;61:1431-9.

7. Ari A, Harwood RJ, Sheard MM, et al. Pressurized metered-dose inhalers versus nebulizers in the treatment of mechanically ventilated subjects with artificial airways: an in vitro study. Respir Care 2015;60:1570-4.

8. Fink J. Aerosol Drug Therapy. In: KacMarek RM, Stoller JK, Heuer AJ, editors. Egan's Fundamentals of Respiratory Care 10th ed. St. Louis, MO: Elsevier-Mosby 2013: 849-73.

9. Miller DD, Amin MM, Palmer LB, et al. Aerosol delivery and modern mechanical ventilation: in vitro/in vivo evaluation. Am J Respir Crit Care Med 2003;168:1205-9.

10. Liu CY, Ko HK, Fink JB, et al. Size distribution of colistin delivery by different type nebulizers and concentrations during mechanical ventilation. Pharmaceutics 2019;11:459.

11. Yang SH, Yang TM, Lin HL, et al. Size distribution of salbutamol/ipratropium aerosols produced by different nebulizers in the absence and presence of heat and humidification. Pulm Pharmacol Ther 2018;48:22-7.

12. Alzahrany M, Van Rhein T, Banerjee A, et al. Fluid flow and particle transport in mechanically ventilated airways. Part II: particle transport. Med Biol Eng Comput 2016;54:1097-109.

13. Gardenhire DS, Burnett D, Strickland S, et al. Aerosol Delivery Devices for Respiratory Therapists. Irving, TX: American Association for Respiratory Care, 2017.

14. Ari A. Aerosol therapy in pulmonary critical care. Respir Care 2015;60:858-874.

15. Wang L, Guan C, Qin X, et al. Effects of aerosol inhalation on respiratory mechanical parameters under different ventilation patterns and ventilator parameters. Zhonghua Wei Zhong Bing Ji Jiu Yi Xue 2018;30:1036-40.

16. Wan GH, Lin HL, Fink JB, et al. In vitro evaluation 
of aerosol delivery by different nebulization modes in pediatric and adult mechanical ventilators. Respir Care 2014;59:1494-500.

17. Carvalho TC, McConville JT. The function and performance of aqueous aerosol devices for inhalation therapy. J Pharm Pharmacol 2016;68:556-78.

18. Steckel H, Eskandar F. Factors affecting aerosol performance during nebulization with jet and ultrasonic nebulizers. Eur J Pharm Sci 2003;19:443-55.

19. Watts AB, McConville JT, Williams RO. Current therapies and technological advances in aqueous aerosol drug delivery. Drug Dev Ind Pharm 2008;34:913-22.

20. Harvey CJ, O'Doherty MJ, Page CJ, et al. Comparison of jet and ultrasonic nebulizer pulmonary aerosol deposition during mechanical ventilation. Eur Respir J 1997;10: 905-9.

21. ElHansy MHE, Boules ME, El Essawy AFM, et al. Inhaled salbutamol dose delivered by jet nebulizer, vibrating mesh nebulizer and metered dose inhaler with spacer during invasive mechanical ventilation. Pulm Pharmacol Ther 2017;45:159-63.

22. Dugernier J, Reychler G, Wittebole X, et al. Aerosol delivery with two ventilation modes during mechanical ventilation: a randomized study. Ann Intensive Care 2016;6:73.

23. Rau JL, Harwood RJ, Groff JL. Evaluation of a reservoir device for metered-dose bronchodilator delivery to intubated adults. An in vitro study. Chest 1992;102: 924-30.

24. Rau JL, Dunlevy CL, Hill RL. A comparison of inline MDI actuators for delivery of a beta agonist and a corticosteroid with a mechanically ventilated lung model. Respir Care 1998;43:705-12.

25. Waugh JB, Jones DF, Aranson R, et al. Bronchodilator response with use of OptiVent versus Aerosol Cloud Enhancer metered-dose inhaler spacers in patients receiving ventilatory assistance. Heart Lung 1998;27: 418-23.

26. Smyth HDC, Beck VP, Williams D, et al. The influence of formulation and spacer device on the in vitro performance of solution chlorofluorocarbon-free propellant-driven metered dose inhalers. AAPS PharmSciTech 2004;5:E7.

27. Fink JB, Dhand R, Grychowski J, et al. Reconciling in vitro and in vivo measurements of aerosol delivery from a metered-dose inhaler during mechanical ventilation and defining efficiency-enhancing factors. Am J Respir Crit Care Med 1999;159:63-8.

28. Dhand R. How should aerosols be delivered during invasive mechanical ventilation? Respir Care 2017;62:1343-67.

29. Dhanani JA, Tang P, Wallis SC, et al. Characterisation of $40 \mathrm{mg} / \mathrm{ml}$ and $100 \mathrm{mg} / \mathrm{ml}$ tobramycin formulations for aerosol therapy with adult mechanical ventilation. Pulm Pharmacol Ther 2018;50:93-9.

30. Tang P, Chan HK, Rajbhandari D, et al. Method to introduce mannitol powder to intubated patients to improve sputum clearance. J Aerosol Med Pulm Drug Deliv 2011;24:1-9.

31. Dalby R, Spallek M, Voshaar T. A review of the development of Respimat ${ }^{\circledR}$ Soft Mist ${ }^{\mathrm{TM}}$ Inhaler. Int J Pharm 2004;283:1-9.

32. Dhand R, Eicher J, Hänsel M, et al. Improving usability and maintaining performance: human-factor and aerosolperformance studies evaluating the new reusable Respimat inhaler. Int J Chron Obstruct Pulmon Dis 2019;14:509-23.

33. Dellweg D, Wachtel H, Höhn E, et al. In vitro validation of a Respimat@ adapter for delivery of nhaled bronchodilators during mechanical ventilation. J Aerosol Med Pulm Drug Deliv 2011;24:285-92.

34. Suggett J, Nagel M. Assessment of a ventilator circuit adapter to be used in conjunction with the Respimat* Soft Mist Inhaler (SMI): Eur Respiratory Soc, 2017. Available online: https://erj.ersjournals.com/content/50/suppl_61/ PA2 100

35. Fang TP, Chen YJ, Yang TM, et al. Optimal connection for Tiotropium SMI delivery through mechanical ventilation: an in vitro study. Pharmaceutics 2020;12:291.

36. O'Riordan TG, Weinstein MD, Mao Y. Bench testing of nebulizers: a comparison of three methods. J Aerosol Med 1999;12:59-66.

37. Hassan A, Salah Eldin R, Abdelrahman MM, et al. Invitro/in-vivo comparison of inhaled salbutamol dose delivered by jet nebulizer, vibrating mesh nebulizer and metered dose inhaler with spacer during non-invasive ventilation. Exp Lung Res 2017;43:19-28.

38. Ari A, Areabi H, Fink JB. Evaluation of aerosol generator devices at 3 locations in humidified and non-humidified circuits during adult mechanical ventilation. Respir Care 2010;5 5:837-44.

39. Lin HL, Fink JB, Zhou Y, et al. Influence of moisture accumulation in inline spacer on delivery of aerosol using metered-dose inhaler during mechanical ventilation. Respir Care 2009;54:1336-41.

40. Moustafa IOF, ElHansy MHE, Al Hallag M, et al. Clinical outcome associated with the use of different inhalation method with and without humidification in asthmatic 
mechanically ventilated patients. Pulm Pharmacol Ther 2017;45:40-6.

41. Lange CF, Finlay WH. Overcoming the adverse effect of humidity in aerosol delivery via pressurized metered-dose inhalers during mechanical ventilation. Am J Respir Crit Care Med 2000;161:1614-8.

42. Fink JB, Dhand R, Duarte AG, et al. Aerosol delivery from a metered-dose inhaler during mechanical ventilation. An in vitro model. Am J Respir Crit Care Med 1996;154: 382-7.

43. Moustafa IOF, Ali MRA, Al Hallag M, et al. Lung deposition and systemic bioavailability of different aerosol devices with and without humidification in mechanically ventilated patients. Heart Lung 2017;46:464-7.

44. Ari A, Dang T, Al Enazi FH, et al. Effect of heat moisture exchanger on aerosol drug delivery and airway resistance in simulated ventilator-dependent adults using jet and mesh nebulizers. J Aerosol Med Pulm Drug Deliv 2018;31:42-8.

45. O'Doherty MJ, Thomas SH, Page CJ, et al. Delivery of a nebulized aerosol to a lung model during mechanical ventilation. Effect of ventilator settings and nebulizer type, position, and volume of fill. Am Rev Respir Dis 1992;146:383-8.

46. Fink JB, Dhand R. Aerosol therapy in mechanically ventilated patients: Recent advances and new techniques. Semin Respir Crit Care Med 2000;21:183-201.

47. Moraine JJ, Truflandier K, Vandenbergen N, et al. Placement of the nebulizer before the humidifier during mechanical ventilation: Effect on aerosol delivery. Heart Lung 2009;38:435-9.

48. Ari A, Atalay OT, Harwood R, et al. Influence of nebulizer type, position, and bias flow on aerosol drug delivery in simulated pediatric and adult lung models during mechanical ventilation. Respir Care 2010;55:845-51.

49. Berlinski A, Willis JR. Effect of tidal volume and nebulizer type and position on albuterol delivery in a pediatric model of mechanical ventilation. Respir Care 2015;60:1424-30.

50. Anderson AC, Dubosky MN, Fiorino KA, et al. The effect of nebulizer position on aerosolized epoprostenol delivery in an adult lung model. Respir Care 2017;62:1387-95.

51. DiBlasi RM, Crotwell DN, Shen S, et al. Iloprost drug delivery during infant conventional and high-frequency oscillatory ventilation. Pulm Circ 2016;6:63-9.

52. Dugernier J, Wittebole X, Roeseler J, et al. Influence of inspiratory flow pattern and nebulizer position on aerosol delivery with a vibrating-mesh nebulizer during invasive mechanical ventilation: an in vitro analysis. J Aerosol Med Pulm Drug Deliv 2015;28:229-36.
53. Hess DR, Dillman C, Kacmarek RM. In vitro evaluation of aerosol bronchodilator delivery during mechanical ventilation: pressure-control vs. volume control ventilation. Intensive Care Med 2003;29:1145-50.

54. Ge HQ, Wang JM, Lin HL, et al. Effect of nebulizer location and spontaneous breathing on aerosol delivery during airway pressure release ventilation in bench testing. J Aerosol Med Pulm Drug Deliv 2019;32:34-9.

55. Mouloudi E, Katsanoulas K, Anastasaki M, et al. Bronchodilator delivery by metered-dose inhaler in mechanically ventilated COPD patients: influence of endinspiratory pause. Eur Respir J 1998;12:165-9.

56. Mouloudi E, Katsanoulas K, Anastasaki M, et al. Bronchodilator delivery by metered-dose inhaler in mechanically ventilated COPD patients: influence of tidal volume. Intensive Care Med 1999;25:1215-21.

57. Mouloudi E, Prinianakis G, Kondili E, et al. Effect of inspiratory flow rate on beta2-agonist induced bronchodilation in mechanically ventilated COPD patients. Intensive Care Med 2001;27:42-6.

58. Fang TP, Lin HL, Chiu SH, et al. Aerosol delivery using jet nebulizer and vibrating mesh nebulizer during high frequency oscillatory ventilation: an in vitro comparison. J Aerosol Med Pulm Drug Deliv 2016;29:447-53.

59. Berkenbosch JW, Grueber RE, Graff GR, et al. Patterns of helium-oxygen (heliox) usage in the critical care environment. J Intensive Care Med 2004;19:335-44.

60. Corcoran TE, Shortall BP, Kim IK, et al. Aerosol drug delivery using heliox and nebulizer reservoirs: results from an MRI-based pediatric model. J Aerosol Med 2003;16:263-71.

61. O'Callaghan C, White J, Jackson J, et al. The effects of Heliox on the output and particle-size distribution of salbutamol using jet and vibrating mesh nebulizers. J Aerosol Med 2007;20:434-44.

62. Kim IK, Saville AL, Sikes KL, et al. Heliox-driven albuterol nebulization for asthma exacerbations: an overview. Respir Care 2006;51:613-8.

63. Garner SS, Wiest DB, Stevens CE, et al. Effect of heliox on albuterol delivery by metered-dose inhaler in pediatric in vitro models of mechanical ventilation. Pharmacotherapy 2006;26:1396-402.

64. Brown MK, Willms DC. A laboratory evaluation of 2 mechanical ventilators in the presence of helium-oxygen mixtures. Respir Care 2005;50:354-60.

65. Goode ML, Fink JB, Dhand R, et al. Improvement in aerosol delivery with helium-oxygen mixtures during mechanical ventilation. Am J Respir Crit Care Med 
2001;163:109-14.

66. Tassaux D, Jolliet P, Thouret JM, et al. Calibration of seven ICU ventilators for mechanical ventilation with helium-oxygen mixtures. Am J Respir Crit Care Med 1999;160:22-32.

67. McGrath JA, O'Sullivan A, Bennett G, et al. Investigation of the quantity of exhaled aerosols released into the environment during nebulisation. Pharmaceutics 2019;11:75.

68. Ehrmann S, Roche-Campo F, Bodet-Contentin L, et al. Aerosol therapy in intensive and intermediate care units: prospective observation of 2808 critically ill patients. Intensive Care Med 2016;42:192-201.

69. Zhang Z, Xu P, Fang Q, et al. Practice pattern of aerosol therapy among patients undergoing mechanical ventilation in mainland China: A web-based survey involving 447 hospitals. PLoS One 2019;14:e0221577.

70. Ari A, Fink JB, Pilbeam SP. Secondhand aerosol exposure during mechanical ventilation with and without expiratory filters: An in-vitro study. Indian J Respir Care 2016;5: 677-82.

Cite this article as: Lin HL, Fink JB, Ge H. Aerosol delivery via invasive ventilation: a narrative review. Ann Transl Med 2021;9(7):588. doi: 10.21037/atm-20-5665
71. Hu HC, Liu HC, Chen YH, et al. The impact of aerosolized mucolytic agents on the airflow resistance of bacterial filters used in mechanical ventilation. J Formos Med Assoc 2015;114:717-21.

72. Marik P, Hogan J, Krikorian J. A comparison of bronchodilator therapy delivered by nebulization and metered-dose inhaler in mechanically ventilated patients. Chest 1999;115:1653-7.

73. Duarte AG, Momii K, Bidani A. Bronchodilator therapy with metered-dose inhaler and spacer versus nebulizer in mechanically ventilated patients: comparison of magnitude and duration of response. Respir Care 2000;45:817-23.

74. Mirza S, Clay RD, Koslow MA, et al. COPD Guidelines: A review of the 2018 GOLD Report. Mayo Clin Proc 2018;93:1488-502.

75. van Meenen DMP, van der Hoeven SM, Binnekade JM, et al. Effect of on-demand vs routine nebulization of acetylcysteine with salbutamol on ventilator-free days in intensive care unit patients receiving invasive ventilation: a randomized clinical trial. JAMA 2018;319:993-1001. 